\section{Primary Liposarcoma of the Stomach Resected Endoscopically}

A 58-year-old Japanese male was referred to our hospital in December 1991, with a provisional diagnosis of a gastric polypoid lesion. The barium meal and endoscopy showed a smoothly elevated hemispheric lesion at the greater curvature of the antrum (Figure 1). Endoscopic ultrasonography (EUS) disclosed a well-demarcated mass, measuring $1.3 \times 0.5 \mathrm{~cm}$, located in the third layer of the gastric wall (Figure 2). Its echo pattern was relatively homogeneous, and slightly more echogenic than the normal submucosa. Based on these clinical findings, the presumptive diagnosis was a benign submucosal tumor (SMT), probably lipoma. Endoscopic resection (ER) was carried out using the snare resection technique. The tumor was histologically diagnosed as liposarcoma with both pleomorphic and myxoid patterns $(1,2)$. A partial gastrectomy was therefore also performed. No signs of recurrence were detectable one year after the operation.

In the literature, the first case of liposarcoma of the stomach was reported by Abrams and Turberville in 1941 (3), and up to now, only eleven cases, including ours, have been reported. Ours was the first case of liposarcoma of the stomach in which EUS and ER were performed. EUS has been reported as the most useful examination to define the presumptive nature of SMT $(4,5)$. However, our case showed that it is still difficult to differentiate between benign and malignant SMTs by means of EUS alone, particularly when the lesion is small. Therefore, for diagnostic and therapeutic purposes, ER is recommended even in small SMTs of the stomach.

\section{References}

1. Enzinger FM, Weiss SW: Soft tissue tumors. St. Louis: Mosby, $1988 ; 346-382$.

2. Enzinger FM, Winslow DJ: Liposarcoma: a study of 103 cases. Virchows Arch Path Anat 1962; 335: 367-388.

3. Abrams MJ, Truberville JS: Liposarcoma of the stomach. South Surg 1941; 10: 891-896.

4. Sato T, Ikeda M, Fujino M, et al.: Diagnosis and treatment of submucosal tumor of gastrointestinal tract [in Japanese]. Gastroenterol Endosc 1992; 34: 342-351.

5. Armengol AM, Benjamin S, Binmoeller K, et al,: Clinical applications of endoscopic ultrasonography in gastroenterology: state of the art 1993: Endoscopy 1993. 25: 358-366.

K. Yamamoto', N. Teramae', H. Uehira', N. Wakabayashi', S. Fukuda ${ }^{\text {I }}$ T. Kodama ${ }^{l}$, K. Kashima ${ }^{l}$, Y. Tsuchihashi ${ }^{2}$

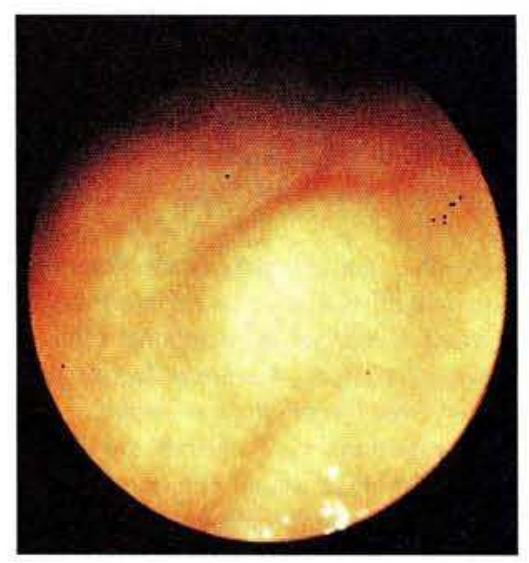

Figure 1: Endoscopic examination showing the submucosal tumor on the greater curvature of the antrum.

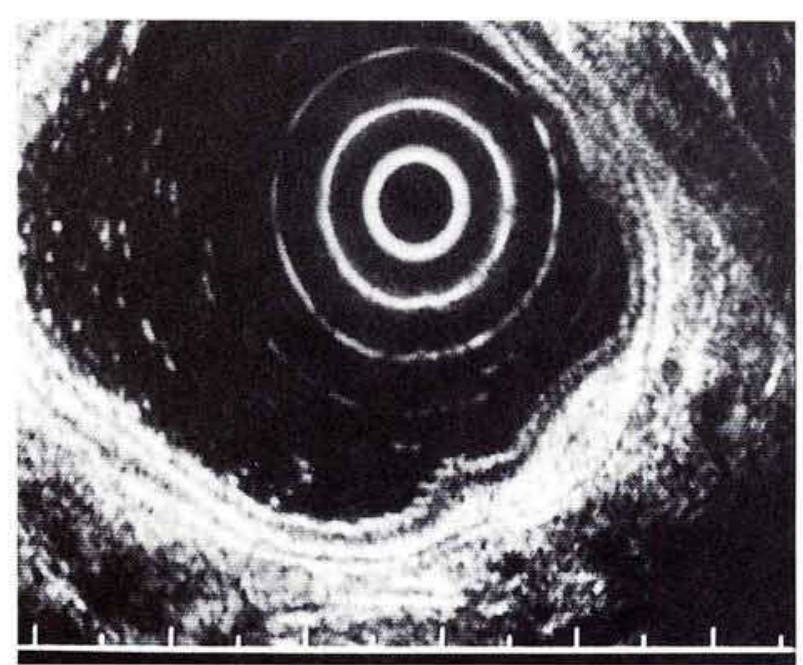

Figure 2: Endoscopic ultrasonography disclosed a well-demarcated high echoic mass located in the third layer.

'Third Department of Medicine

${ }^{2}$ Hospital Department of Pathology, Kyoto Prefectural University of Medicine, Kyoto, Japan

Corresponding Author

K. Yamamoto, M.D.

Third Department of Internal Medicine, Kyoto Prefectural University of Medicine, 465 Kajii-cho, Kamigyo-ku, Kyoto 602, Japan 